\title{
Flow Characteristics and Robustness of an Inclined Quad-vortex Range Hood
}

\author{
Jia-Kun CHEN ${ }^{1 *}$ and Rong Fung HUANG ${ }^{2}$ \\ ${ }^{1}$ Graduate Institute of Applied Science and Technology, National Taiwan University of Science and Technology, \\ Taiwan \\ ${ }^{2}$ Department of Mechanical Engineering, National Taiwan University of Science and Technology, Taiwan
}

Received July 15, 2013 and accepted February 18, 2014

Published online in J-STAGE February 28, 2014

\begin{abstract}
A novel design of range hood, which was termed the inclined quad-vortex (IQV) range hood, was examined for its flow and containment leakage characteristics under the influence of a plate sweeping across the hood face. A flow visualization technique was used to unveil the flow behavior. Three characteristic flow modes were observed: convex, straight, and concave modes. A tracer gas detection method using sulfur hexafluoride $\left(\mathrm{SF}_{6}\right)$ was employed to measure the containment leakage levels. The results were compared with the test data reported previously in the literature for a conventional range hood and an inclined air curtain (IAC) range hood. The leakage $\mathrm{SF}_{6}$ concentration of the IQV range hood under the influence of the plate sweeping was $0.039 \mathrm{ppm}$ at a suction flow rate of $9.4 \mathrm{~m}^{3} / \mathrm{min}$. The leakage concentration of the conventional range hood was $0.768 \mathrm{ppm}$ at a suction flow rate of $15.0 \mathrm{~m}^{3} / \mathrm{min}$. For the IAC range hood, the leakage concentration was $0.326 \mathrm{ppm}$ at a suction flow rate of $10.9 \mathrm{~m}^{3} / \mathrm{min}$. The IQV range hood presented a significantly lower leakage level at a smaller suction flow rate than the conventional and IAC range hoods due to its aerodynamic design for flow behavior.
\end{abstract}

Key words: Range hood, Flow visualization, Tracer gas, Robustness, Concentration measurement

\section{Introduction}

Cooking produces air pollutants, moisture, and odors ${ }^{1,2)}$. Residential gas cooking burners also emit air pollutants ${ }^{3,4)}$ at rates that can lead to indoor concentrations exceeding health-based standards ${ }^{5}$. Removal of these contaminants is important for maintaining acceptable indoor air quality in homes. When gas cooking is used in kitchens, the cooking procedure generates various pollutants, like carbon monoxide, oxides of nitrogen (NOx), and particulate matter (PM). Many different types of appliances are used for heating, cooking, and supplying hot water ${ }^{6-8)}$. Previous

*To whom correspondence should be addressed. E-mail: jkchen29@mail.ntust.edu.tw

C2014 National Institute of Occupational Safety and Health studies have reported indoor air pollution from various heating systems ${ }^{9-11)}$.

Range hoods are the primary ventilation device for exhausting the contaminants produced in kitchens. Conventional range hoods basically have one or two circular holes fitted with fans and ducts to exhaust contaminants. Previous studies, by either measuring or modeling, have reported the capture efficiencies of various conventional range hoods ${ }^{12-15)}$. Hunt and Ingham ${ }^{16)}$ presented a mathematical model for the air flow pattern of an exhaust ventilation hood. Abanto and Marcelo ${ }^{17)}$ reported the flow field around a range hood obtained by using a computational fluid dynamics code. Recently, Chen et al. ${ }^{18)}$ and Huang et al. ${ }^{19)}$ used the laser-assisted flow visualization technique and $\mathrm{SF}_{6}$ (sulfur hexafluoride) tracer gas detection method to determine the correlation between the flow 
field characteristics and the containment leakage levels of the conventional range hood. They found that the leakage of the conventional range hood is primarily induced by the inappropriate aerodynamic design of the hood. The hood must be installed at a distance about six to eight suction opening diameters from the counter top in order to allow for the cook's hand movements, but this produces an insufficient upward flow velocity at the pollutant generation altitude to carry the fumes. Influences of cross draughts, cook presence, and cook's movements are detrimental to the performance of conventional range hoods. Reducing oil fume leakage levels by increasing the suction flow rate is a straight forward method but may not be the best to solve the problem because a drastic increase in the suction flow rate would be accompanied by significant energy consumption and a higher noise level. Huang et al. ${ }^{20 \text {, }}$

${ }^{21)}$ represented an inclined air-curtain (IAC) range hood which was designed by combining a suction slot installed at the hood and a plane jet arranged at the front part of the countertop to form a backward-inclined push-pull air curtain. They showed that the IAC range hood has higher performance than the conventional range hoods under both the static and dynamic tests. However, the leakages were still not negligibly small.

The inclined quad-vortex (IQV) range hood has been shown to present high containment performance due to its special aerodynamic design. In order to compare the performance characteristics among the conventional, IAC, and IQV range hoods, we performed experimental studies on the robustness of the IQV range hood and compared the results with the published experimental data of the conventional and IAC hoods. The sweeping plate method, which was referred to in the robustness test methodology for the chemical fume hood proposed by the European Committee for Standardization ${ }^{22)}$, was used. The laserassisted smoke flow visualization technique was used to determine the qualitative flow behaviors and the tracer gas detection method was employed to quantify the leakage levels of the hood.

\section{Materials and Methods}

\section{IQV range hood and test rig}

The configurations of the IQV range hood used for the experiments are shown in Fig. 1. The hood consisted of three features that are different from the conventional range hoods. First, a suction slot $(60 \mathrm{~cm} \times 2 \mathrm{~cm})$ was located at the bottom face of the hood. Second, two jets provided by cross flow fans blowing down through the slots $(30 \mathrm{~cm} \times 2 \mathrm{~cm})$ were arranged at the bottom face of the hood. Third, two side plates $(40 \mathrm{~cm} \times 55 \mathrm{~cm})$ were installed at the lateral ends of the hood. The hood had a depth of $50 \mathrm{~cm}$ and a width of $W$, which is variable from $90 \mathrm{~cm}$ to $120 \mathrm{~cm}$. The hood was installed at a height of $60 \mathrm{~cm}$ above the countertop. An air box was installed on the hood to accumulate the air and oil fumes drawn from the suction slot and to exhaust the mixture to the outdoors. Half circular arcs with a radius of $2.5 \mathrm{~cm}$ were installed at the front edges of the hood and the side plates to guide the flow. The gap between the bottom edges of the side plates and the countertop was $5 \mathrm{~cm}$. The distance between the front edge of the countertop and the front edges of the side plates was $10 \mathrm{~cm}$.

The countertop (128 $\mathrm{cm}$ in width and $60 \mathrm{~cm}$ in depth) had a height of $86 \mathrm{~cm}$ from the ground level. Two electric heaters with hot plates on their tops were imbedded under the countertop with $7 \mathrm{~cm}$ protruding upward. Circular oil pans were placed on the hot plates of the electric heaters. The diameter and height of the oil pans were $28 \mathrm{~cm}$ and $6 \mathrm{~cm}$, respectively.

\section{Flow visualization}

The laser-assisted smoke flow visualization technique was used to reveal the patterns of the oil mist in the flow. Mineral oil was poured into the oil pans and heated to $230{ }^{\circ} \mathrm{C}$ by the hot plates. The smoke (i.e., the oil mists) was generated and rose up from the oil pans. The diameter of the oil mist particles, measured by a particle analyzer (Model 2600C, Malvern Instrument Ltd., Malvern, Worcestershire, UK), was $1.7 \pm 0.2 \mu \mathrm{m}$. A green laser beam was generated from a $100 \mathrm{~mW}$ Nd-YAG laser. The wavelength of the laser beam was $532 \mathrm{~nm}$. The laser beam was passed through a homemade laser-light expander to form a laser-light sheet. The thickness of the laser-light sheet was about $0.5 \mathrm{~mm}$. The oil mists scattered the laser light to describe the flow pattern in the flow field of the IQV range hood. A charge-coupled device (CCD) camera was used to record the images of the oil mists in the plane of the laser-light sheet. The framing rate and the exposure time were $30 \mathrm{fps}$ and $1 / 60 \mathrm{~s}$, respectively.

\section{Robustness test}

Figure 2 shows the configurations of the flat-plate sweeping experiment for the robustness test. The sweeping plate method was based on the robustness test methodology proposed by the European Committee for Standardization ${ }^{22)}$. This method was used to simulate the walk-by motion of people across the front face of a pollutant removing device. 
(a)

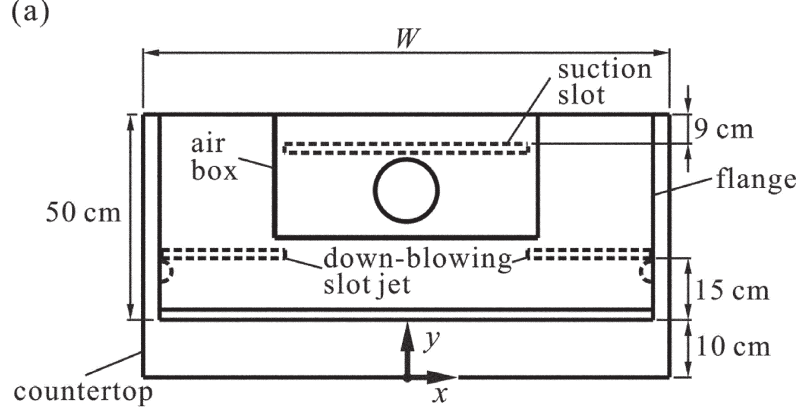

(b)

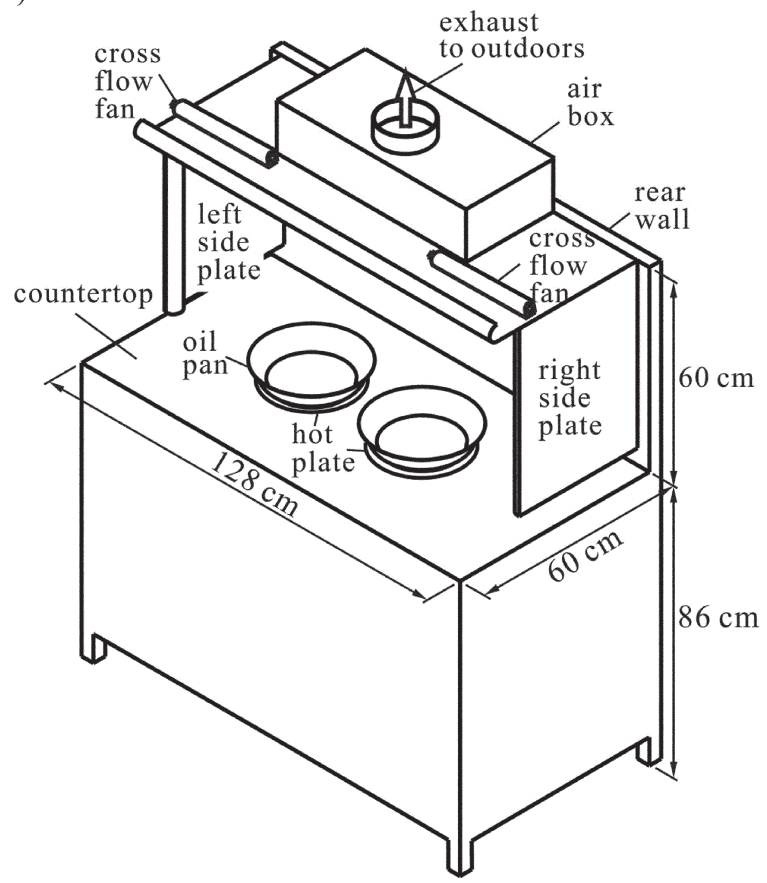

Fig. 1. Configurations of IQV range hood.

(a) top view, (b) isometric view.

A rectangular flat plate was installed upright on a traversing mechanism. The dimensions of the flat plate were $2 \mathrm{~cm}$ (thickness) $\times 40 \mathrm{~cm}$ (width) $\times 150 \mathrm{~cm}$ (height). The plate moved from the right to the left at a velocity of $1 \mathrm{~m} / \mathrm{s}$ across the front area of the range hood. The distance between the inner edge of the flat plate and the front edge of the countertop was denoted as $L$. Two cases of the distance $L$ were tested in the study: $40 \mathrm{~cm}$ and $80 \mathrm{~cm}$. During the experiment for $L=40 \mathrm{~cm}$, as shown in Fig. 2 (a), no mannequin was installed in front of the countertop. For the experiment at $L=80 \mathrm{~cm}$, a mannequin was installed in front of the countertop, as shown in Fig. 2 (b). The height and shoulder width of the mannequin were $158 \mathrm{~cm}$ and $43 \mathrm{~cm}$, respectively. The distance between the chest of the mannequin and the front edge of the range hood was $15 \mathrm{~cm}$. (a)
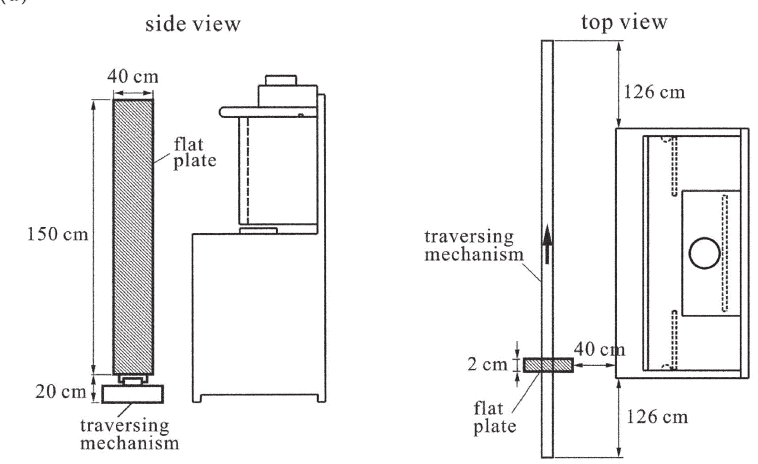

(b)
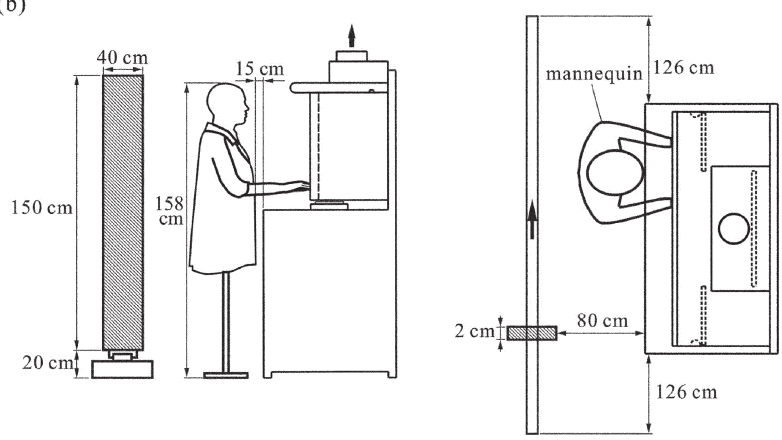

Fig. 2. Arrangement of robustness tests.

(a) $L=40 \mathrm{~cm}$, (b) $L=80 \mathrm{~cm}$.
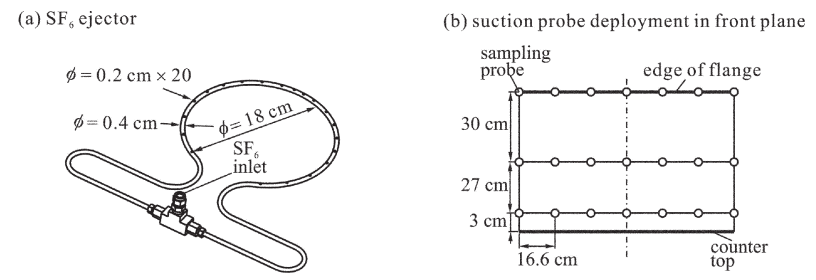

(c) suction probe deployment in left lateral plane (d) sampling probe at breathing zone
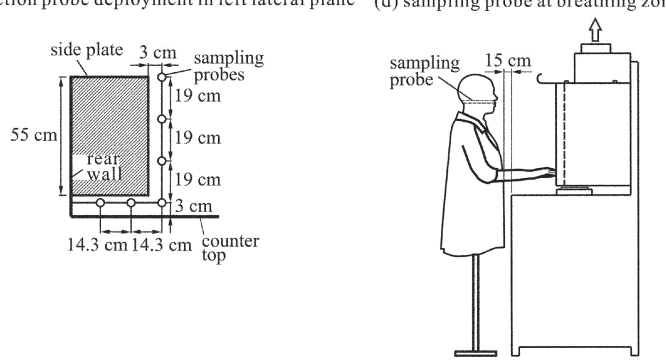

Fig. 3. Tracer gas releasing ring and deployments of sampling probes.

(a) gas releasing ring, (b) suction probe deployment in front plane, (c) suction probe deployment in left lateral plane, (d) sampling probe at breathing zone of a mannequin.

\section{Tracer gas releasing and sampling}

The tracer gas $\left(\mathrm{SF}_{6}\right)$ was released from two home-made gas release rings (Fig. 3 (a)) that were made of copper 
tubes with an outer diameter of $0.4 \mathrm{~cm}$. In total, 20 small holes with diameters of $0.2 \mathrm{~cm}$ were drilled along each gas release ring to eject $\mathrm{SF}_{6}$ gas. A pressure gauge, a needle valve, and a rotameter calibrated with $\mathrm{SF}_{6}$ gas were attached to a piping system to control the flow rate of $\mathrm{SF}_{6}$. The flow rate of $\mathrm{SF}_{6}\left(Q_{\mathrm{SF} 6}\right)$ released from each of the gas release rings was $3 \mathrm{~L} / \mathrm{min}$. The exit velocity of the $\mathrm{SF}_{6}$ from the ejecting holes was thus about $0.8 \mathrm{~m} / \mathrm{s}$. When the experiments were conducted, the gas release rings were placed on the hot plates of the electric heaters in order to receive the heat and buoyancy from the hot plates.

Twenty one sampling probes made of cylindrical stainless tubes were deployed in a plane $10 \mathrm{~cm}$ in front of the hood face (Fig. 3 (b)) and six suction probes were deployed in the left lateral plane of the hood (Fig. 3 (c)). The length and inner diameter of the sampling probes were $10 \mathrm{~cm}$ and $1.3 \mathrm{~cm}$, respectively. The suction velocity at the inlet of each sampling probe was adjusted to a low value, about $3 \mathrm{~cm} / \mathrm{s}$, in order not to significantly disturb the flow patterns. The sampling probes were connected to the inlets of a mixing chamber by Teflon tubes. The detector probe was affixed to the outlet of the mixing chamber. The detection probe was connected to a Miran SapphIRe ${ }^{\mathrm{TM}}$ Portable Ambient Analyzer (Thermo Electron Corp., Franklin, Mass.) via a Teflon tube. The Miran SapphIRe ${ }^{\mathrm{TM}}$ analyzer was used to measure the concentration of the tracer gas. The resolution of the Miran SapphIRe ${ }^{\mathrm{TM}}$ analyzer used to measure the concentration of the tracer gas $\mathrm{SF}_{6}$ was $0.001 \mathrm{ppm}$. The sampling rate was 20 readings per second.

During the experiment for $L=80 \mathrm{~cm}$, an additional sampling probe was installed at the breathing zone of the mannequin. The inlet velocity of the sampling probe was $1 \mathrm{~m} / \mathrm{s}$. The tracer gas concentration around the breathing zone of the mannequin was independently measuredthe sampled mixture was directly delivered to a Miran SapphIRe ${ }^{\mathrm{TM}}$ analyzer through a Teflon pipe without premixing with the mixture sampled by the probes shown in Fig. 3 (b) and (c).

\section{Results and Discussion}

\section{Flow behavior}

Figure 4 shows the flow pattern revealed by oil mists in the horizontal plane $z=20 \mathrm{~cm}$. The suction velocity at the inlet of the suction slot is $V_{\mathrm{s}}=12 \mathrm{~m} / \mathrm{s}$ and the blowing velocity at the exit of the down-blowing jets is $V_{\mathrm{b}}=1.9 \mathrm{~m} /$ s. Oil mists are concentrated in four groups above the oil pans. In the recorded movies that are not shown here, the motion of the oil mists clearly show four counter-rotating

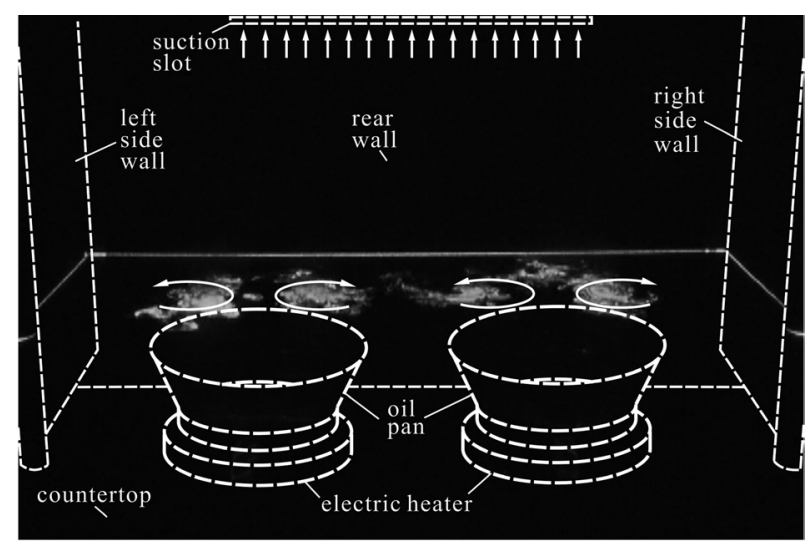

Fig. 4. Flow pattern in horizontal plane. $z=20 \mathrm{~cm} . V_{\mathrm{s}}=12 \mathrm{~m} / \mathrm{s}$ and $V_{\mathrm{b}}=1.9 \mathrm{~m} / \mathrm{s}$.

vortices-neighboring vortices present a counter-rotating motion, as indicated by the arrows in Fig. 4. The oil mists are coherently contained in the rotating vortices so that the dispersion of the oil mists toward the areas near the side plates, rear corners, and hood face is not observed. The pressure in a vortex would be lower than the pressure of its surrounding atmosphere due to the rotating motion of the flow ${ }^{23)}$. The pressure difference increases with an increasing the rotation rate of the vortex. By observing the movies recorded in the study, the rotation rate of the vortices increases with the increasing the suction velocity $V_{\mathrm{s}}$. As the suction velocity is increased beyond about $8 \mathrm{~m} /$ $\mathrm{s}$, the pressure difference between the core regions of the vortices and the surrounding atmosphere becomes large enough to attract and contain the oil mists in the vortices. The scenario in which oil mists are concentrated in four vortices, as shown in Fig. 4, is thus observed. At the suction velocities smaller than or equal to $8 \mathrm{~m} / \mathrm{s}$, four vortical flow motions are still observable (although not very coherent), but some oil mists are dispersed out of the vortices.

In order to better understand the vortex system induced by the IQV range hood, the hand sketch of the topological flow pattern corresponding to Fig. 4 is analyzed and shown in Fig. 5. We obtained the topological sketch by employing the critical point theory, developed by Lighthill $^{24)}$ and Perry and Steiner ${ }^{25)}$. This technique can help to reveal features in the flow field. As shown in Fig. 5, the critical points consist of six 'three-way saddles' $\left(S_{1}{ }^{\prime}-S_{6}\right.$ '), four 'four-way saddles' $\left(S_{1}-S_{4}\right)$, and six full nodes $\left(N_{1}-\right.$ $N_{6}$ ). From the topological point of view, the boundary layers near the leading edges of the side plates separate at the three-way saddles $S_{1}{ }^{\prime}$ and $S_{4}{ }^{\prime}$ then reattach to the downstream parts of the side plates at the three-way saddles $S_{2}{ }^{\prime}$ and $S_{3}{ }^{\prime}$ to form the recirculation bubbles centered at the 


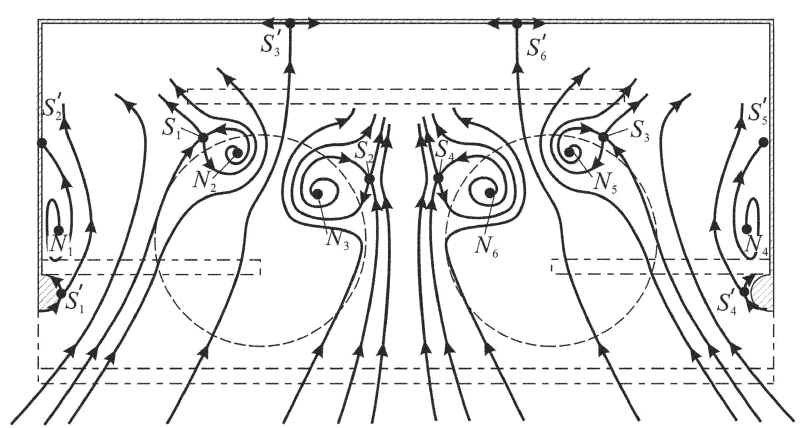

Fig. 5. Topological flow pattern corresponding to Fig. 4.

nodes $N_{1}$ and $N_{4}$. The counter-rotating vortices centered at the nodes $N_{2}, N_{3}, N_{5}$, and $N_{6}$ and the associated four-way saddles $S_{1}, S_{2}, S_{3}$, and $S_{4}$ are formed according to the topological rule that the neighboring separatrices (or streamlines) should not go in opposite directions. For instance, there are alleyways between neighboring vortices in Fig. 5 . In these alleyways between neighboring vortices, the flows all go rearwards. The vortex $N_{3}$ rotates clockwise, which will induce a flow in the opposite direction in the alleyway around the symmetry plane. A saddle point $S_{2}$, therefore, must exist so that the vortex and the flow in the alleyway can coexist. The principle of this example applies to the whole flow field so that the complex flow field in Fig. 4 is formed. The number of nodes and saddles shown in Fig. 5 satisfies the topological rule that found by Hunt $e a^{26)}$.

Figure 6 shows the images of oil mists in the vertical planes $x=0$ and $-20 \mathrm{~cm}$ at $V_{\mathrm{s}}=8 \mathrm{~m} / \mathrm{s}$ and $V_{\mathrm{b}}=0$. In the symmetry plane $x=0$ (Fig. 6 (a)), oil mists incline rearward as they rise toward the suction slot. Two effects may induce the rearward inclination of oil mists - the rearward offset of the suction slot and the Coanda effect ${ }^{27)}$. In the vertical plane across the center of the left oil pan $x=$ $-20 \mathrm{~cm}$ (Fig. 6 (b)), oil mists rising from the front edge of the left oil pan incline rearward at a large inclination angle. It is noted that in both Fig. 6 (a) and (b), oil mists disperse to the area around the front edge of the hood bottom face and form recirculation bubbles. This recirculation bubble would induce a danger of oil mist diffusion and dispersion. The oil mists contained in the recirculation bubble located near the front edge of the hood may disperse if a cook walks by the hood face or stands in front of the hood.

Figure 7 shows the images of oil mists in the vertical planes $x=0$ and $-20 \mathrm{~cm}$ at the suction velocity $V_{\mathrm{s}}=8 \mathrm{~m} / \mathrm{s}$ and $V_{\mathrm{b}}=1.9 \mathrm{~m} / \mathrm{s}$. In the symmetry plane $x=0$ (Fig. 7 (a)), the recirculation bubble shown in Fig. 6 (a) disappears. In the vertical plane $x=-20 \mathrm{~cm}$, as shown in Fig. 7 (b), the recirculation bubble is retracted rearward and is located
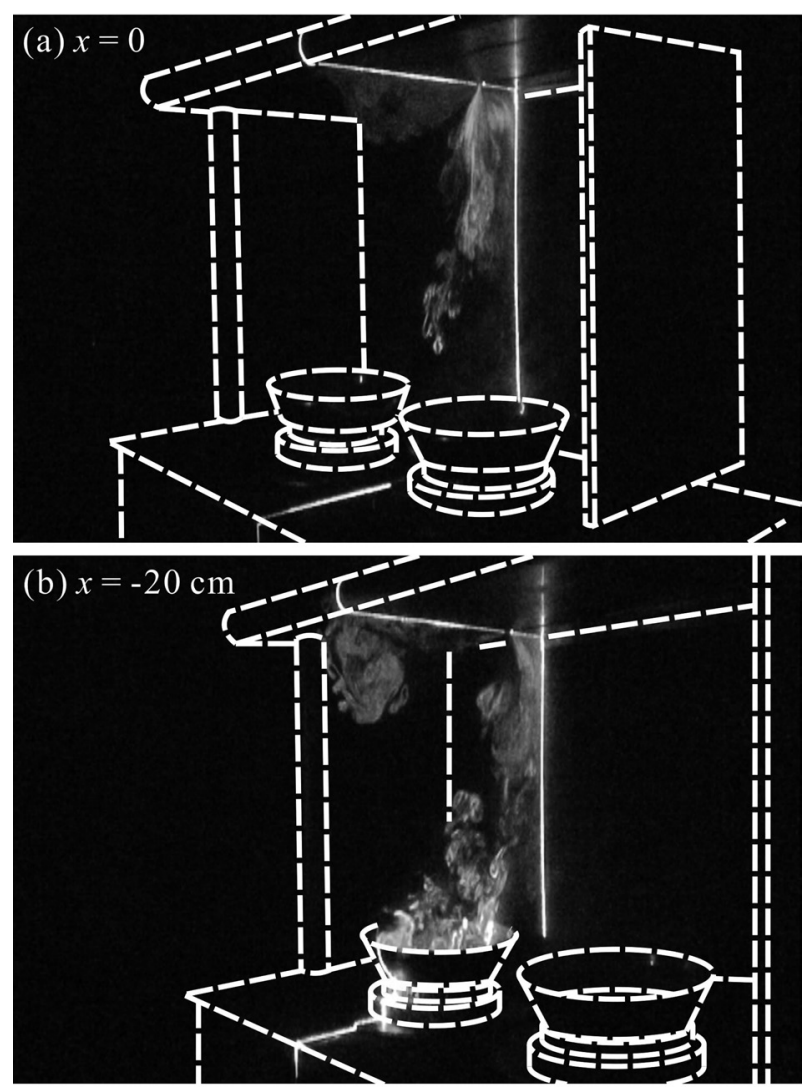

Fig. 6. Oil flow images in vertical planes. (a) $x=0$, (b) $x=-20 \mathrm{~cm}$. $V_{\mathrm{s}}=8 \mathrm{~m} / \mathrm{s}, V_{\mathrm{b}}=0$.

behind the down-blowing jet because the down-blowing jet forms an "air curtain" and isolates the oil mists from dispersing outward.

Figure 8 shows three characteristic flow modes appearing in the vertical plane. At $V_{\mathrm{s}}=8 \mathrm{~m} / \mathrm{s}$ (Fig. 8 (a)), the rearward inclined oil mists present a convex scenario because the suction velocity is not large enough. At the suction velocity $V_{\mathrm{s}}=10 \mathrm{~m} / \mathrm{s}$ (Fig. 8 (b)), the front edge of the oil mists reveals a straight mode. At $V_{\mathrm{s}}=12 \mathrm{~m} / \mathrm{s}$ (Fig. 8 (c)), the rearward inclined oil mists present the concave mode because the Coanda effect is enhanced under this condition. The convex mode appears at $V_{\mathrm{s}} \leq 8 \mathrm{~m} / \mathrm{s}$. The straight mode is observed in the range $8 \mathrm{~m} / \mathrm{s}<V_{\mathrm{s}}<12 \mathrm{~m} / \mathrm{s}$. At $V_{\mathrm{s}}>12$ $\mathrm{m} / \mathrm{s}$, the concave mode presents. As mentioned previously, at $V_{\mathrm{s}} \leq 8 \mathrm{~m} / \mathrm{s}$ we may observe four "loose" vortical flow motions in the horizontal plane with dispersion of oil mists out of the vortices. By comparing this flow mode with the characteristic flow modes appearing in the vertical plane shown in Fig. 8, we may conclude that operating the suction velocity in the range $V_{\mathrm{s}} \leq 8 \mathrm{~m} / \mathrm{s}$ is not enough to set up a strong rearward-inclined vortical flow structured to coherently contain the oil mists in the vortices. 

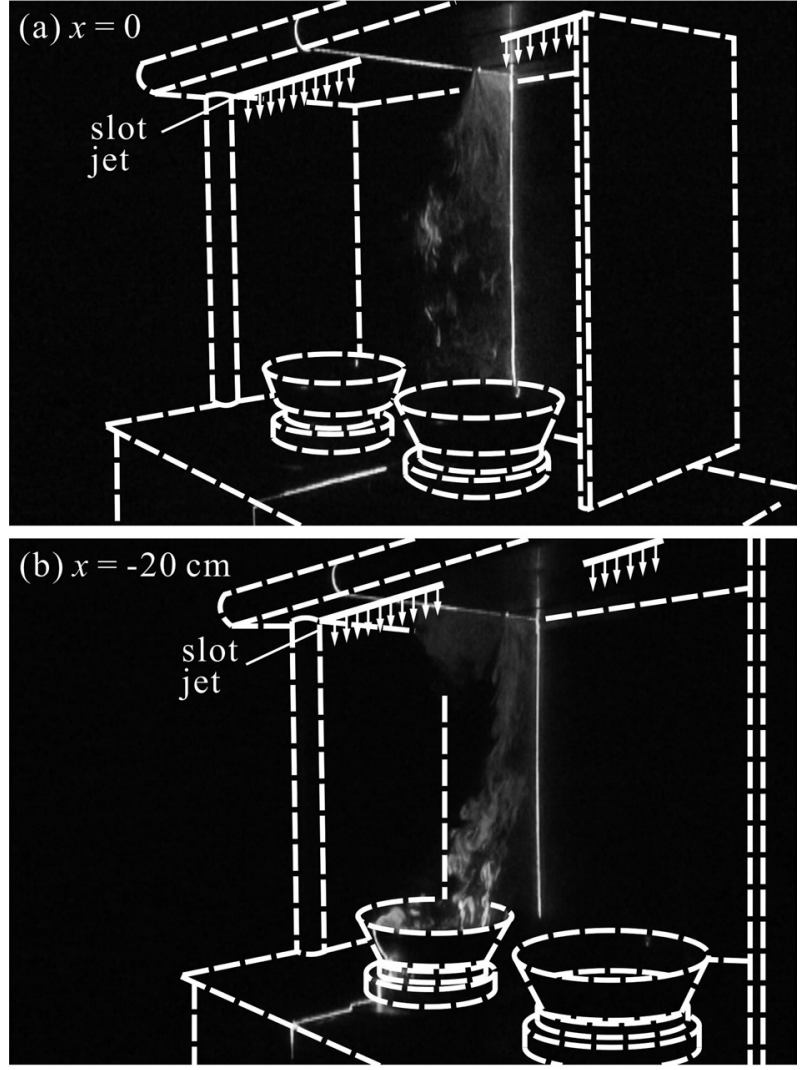

Fig. 7. Oil flow images in vertical planes.

(a) $x=0$, (b) $x=-20 \mathrm{~cm} . V_{\mathrm{s}}=8 \mathrm{~m} / \mathrm{s}, V_{\mathrm{b}}=1.9 \mathrm{~m} / \mathrm{s}$.

Tracer gas leakage concentrations after plate sweeping

Table 1 shows the robustness test results at $L=40 \mathrm{~cm}$ by using the plate-sweeping method (Fig. 2). For comparison, the data for the IAC and conventional range hoods were quoted from Huang et $a l^{20,21)}$. The conventional range hood has a very low robustness. For instance, operating at $Q_{\mathrm{s}}=10.5 \mathrm{~m}^{3} / \mathrm{min}$, the leakage concentration of the conventional range hood is drastically large- $-1.251 \mathrm{ppm}$. At $Q_{\mathrm{s}}=12 \mathrm{~m}^{3} / \mathrm{min}$, the leakage concentration of the conventional range hood is $0.618 \mathrm{ppm}$ while the IQV range hood presents a similar leakage level of $0.601 \mathrm{ppm}$ at a significantly smaller suction flow rate $Q_{\mathrm{s}}=7.2 \mathrm{~m}^{3} /$ min. Operating at $Q_{\mathrm{s}}=9.4 \mathrm{~m}^{3} / \mathrm{min}$, the IQV range hood presents a negligibly small leakage concentration value of $0.039 \mathrm{ppm}$, which is only one-twentieth that of the conventional range hood operating at $Q_{\mathrm{s}}=15 \mathrm{~m}^{3} / \mathrm{min}$ and one-eighth of the IAC range hood operating at $Q_{\mathrm{s}}=10.9$ $\mathrm{m}^{3} / \mathrm{min}$. Apparently, the IQV range hood presents the highest robustness and lowest energy consumption among the three types of range hoods.

Table 2 shows the robustness test results at $L=80 \mathrm{~cm}$. A mannequin is standing in front of the counter for this ex-
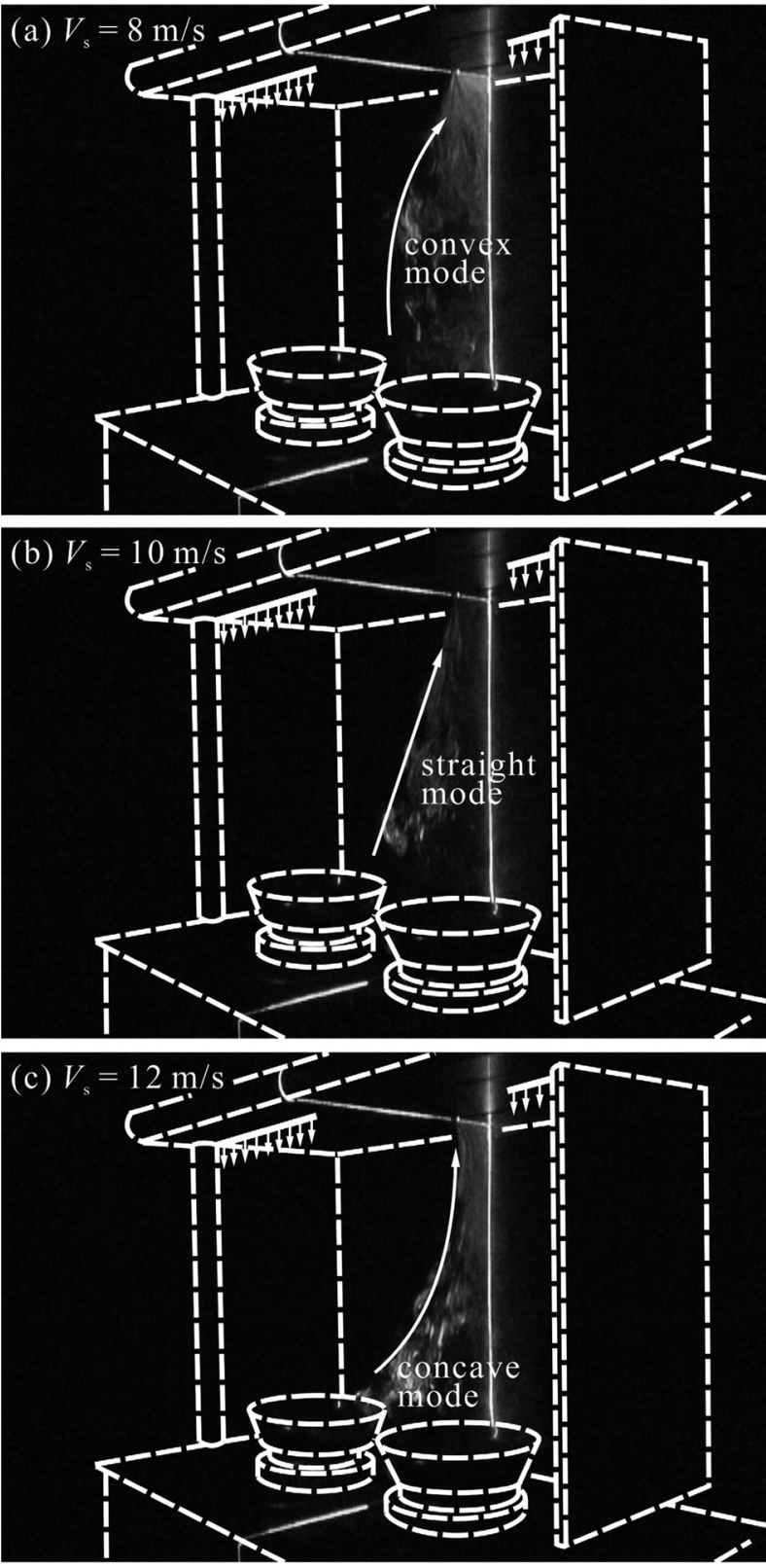

Fig. 8. Characteristic flow modes in vertical plane.

$x=0$. (a) convex mode, $V_{\mathrm{s}}=8 \mathrm{~m} / \mathrm{s}$; (b) straight mode, $V_{\mathrm{s}}=10 \mathrm{~m} / \mathrm{s}$; (c) concave mode, $V_{\mathrm{s}}=12 \mathrm{~m} / \mathrm{s} . V_{\mathrm{b}}=1.9 \mathrm{~m} / \mathrm{s}$.

periment. The test data in Table 2 present negligibly small leakage concentrations under all conditions, revealing two facts. First, the presence of the mannequin does not induce containment leakage. According to Huang et al. ${ }^{19)}$, the presence of a mannequin in front of the conventional range hood would induce a recirculation bubble around the mannequin chest and therefore lead to containment leakage. The leakage concentrations measured at the breathing zone of a mannequin standing in front of a conventional range hood are $17.0 \mathrm{ppm}$ at $Q_{\mathrm{s}}=10.5 \mathrm{~m}^{3} / \mathrm{min}$ and $20.5 \mathrm{ppm}$ at $Q_{\mathrm{s}}$ 
Table 1. Robustness test results of IQV, IAC, and conventional range hoods

\begin{tabular}{|c|c|c|c|c|}
\hline \multirow{2}{*}{$\begin{array}{c}V_{\mathrm{s}} \\
(\mathrm{m} / \mathrm{s})\end{array}$} & \multirow{2}{*}{$\begin{array}{c}Q_{\mathrm{s}} \\
\left(\mathrm{m}^{3} / \mathrm{min}\right)\end{array}$} & IQV & $\begin{array}{c}\text { IAC } \\
\left(\text { Huang et al. }{ }^{21)}\right)\end{array}$ & $\begin{array}{c}\text { Conventional } \\
\text { (Huang et al. }{ }^{20)} \text { ) }\end{array}$ \\
\hline & & \multicolumn{3}{|c|}{$C_{\mathrm{ave}}(\mathrm{ppm})$} \\
\hline 8 & 5.8 & 0.761 & & \\
\hline 10 & 7.2 & 0.601 & & \\
\hline 12 & 8.6 & 0.291 & & \\
\hline 13 & 9.4 & 0.039 & & \\
\hline & 10.5 & & & 1.251 \\
\hline & 10.9 & & 0.326 & \\
\hline & 12.0 & & & 0.618 \\
\hline & 15.0 & & & 0.768 \\
\hline
\end{tabular}

$L=40 \mathrm{~cm}$.

$=15 \mathrm{~m}^{3} / \mathrm{min}$. The leakage concentrations measured at the breathing zone of a mannequin standing in front of an IAC range hood are $0.3 \mathrm{ppm}$ at $Q_{\mathrm{s}}=10.1 \mathrm{~m}^{3} / \mathrm{min}$ and $0.1 \mathrm{ppm}$ at $Q_{\mathrm{s}}=11.8 \mathrm{~m}^{3} / \mathrm{min}$. In Table 2, the leakage concentrations of the IQV range hood measured at the breathing zone are all negligibly small. This can be explained by the rearward inclination of the vortical flows. The rearward inclined vortical flows that contain the oil mists are located far from the recirculation bubble induced by the mannequin presence, and therefore the entrainment and dispersion effects are weakened. Second, the plate sweeping across the back area of the mannequin does not induce containment leakage. This happens because the wake flow induced by the plate is generally not wide enough to reach the hood face situated at $80 \mathrm{~cm}$ away.

\section{Conclusions}

The IQV range hood employed a narrow suction slot and two side plates to generate a flow field containing four rearward-inclined counter rotating vortices. The counter rotating vortical flows were formed applying topological reasoning to the flow dynamics. The boundary layer separations occurring at the leading edges of the side plates induced two corner vortices. The corner vortices subsequently induced two outer vortices. These two outer vortices together with the central rearward-going flow further induced two counter rotating inner vortices. As a result of the low pressure inside the vortical flows, the oil mists were coherently contained in the inner and outer counter rotating vortices at the suction velocities greater than about $8 \mathrm{~m} / \mathrm{s}$. The vortical flows rose up with spiral motions and inclined rearward owing to the effects induced by the rearward offset of the suction slot and Coanda effect.
Table 2. Robustness test results of IQV range hood at various hood width

\begin{tabular}{|c|c|c|c|c|c|c|c|}
\hline \multirow{4}{*}{$\begin{array}{c}V_{\mathrm{s}} \\
(\mathrm{m} / \mathrm{s})\end{array}$} & \multirow{4}{*}{$\begin{array}{c}Q_{\mathrm{s}} \\
\left(\mathrm{m}^{3} / \mathrm{min}\right)\end{array}$} & \multicolumn{3}{|c|}{$\begin{array}{c}\text { Normal probe } \\
\text { deployment }\end{array}$} & \multicolumn{3}{|c|}{$\begin{array}{l}\text { Breathing zone } \\
\text { of mannequin }\end{array}$} \\
\hline & & \multicolumn{6}{|c|}{$W(\mathrm{~cm})$} \\
\hline & & 90 & 100 & 120 & 90 & 100 & 120 \\
\hline & & \multicolumn{6}{|c|}{$C_{\text {ave }}(\mathrm{ppm})$} \\
\hline 8 & 5.8 & $<0.001$ & $<0.001$ & 0.002 & $<0.001$ & 0.001 & $<0.001$ \\
\hline 10 & 7.2 & $<0.001$ & $<0.001$ & $<0.001$ & $<0.001$ & 0.002 & $<0.001$ \\
\hline 12 & 8.6 & $<0.001$ & $<0.001$ & 0.001 & $<0.001$ & 0.001 & $<0.001$ \\
\hline 13 & 9.4 & $<0.001$ & $<0.001$ & $<0.001$ & $<0.001$ & $<0.001$ & 0.001 \\
\hline
\end{tabular}

Three characteristic flow modes were observed: convex, straight, and concave. The convex flow mode corresponded to a suction velocity of less than or equal to $8 \mathrm{~m} /$ $\mathrm{s}$ that the oil mists may disperse out of the counter rotating vortices. The robustness tests performed by the sweeping plate method showed that the IQV range hood presented a negligibly small leakage concentration value which is drastically lower than those of the conventional and IAC range hoods. The IQV range hood presented the highest robustness and lowest energy consumption among the three types of range hoods. This high performance may be explained by the rearward inclination of the vortical flows created by the configurations of the IQV range hood.

\section{Acknowledgement}

The authors gratefully acknowledge the financial support provided to this study by the National Science Council of Taiwan under Grant No. NSC 101-2218-E-011-030.

\section{References}

1) Li CS, Lin WH, Jenq FT (1993) Size distributions of submicrometer aerosols from cooking. Environ Int 19, 147-54. [CrossRef]

2) Wallace LA, Emmerich SJ, Howard-Reed C (2004) Source strengths of ultrafine and fine particles due to cooking with a gas stove. Environ Sci Technol 38, 2304-11. [Medline] [CrossRef]

3) Traynor GW, Apte MG, Chang GM (1996) Pollutant emission factors from residential natural gas appliances: A literature review. Lawrence Berkeley National Laboratory, Berkeley, CA.

4) Singer BC, Apte MG, Black DR, Hotchi T, Lucas D, Lunden MM, Mirer AG, Spears M, Sullivan DP (2009) Natural gas variability in California: environmental impacts and device performance: experimental evaluation of 
pollutant emissions from residential appliances. Lawrence Berkeley National Laboratory, Berkeley.

5) Ko YC, Lin TH (2003) Emissions and efficiency of a domestic gas stove burning natural gases with various compositions. Energy Convers Manage 44, 3001-14. [CrossRef]

6) Godish T (2001). Indoor Environmental Quality. CRC Press, Boca Raton.

7) Gao J, Cao C, Xiao Q, Xu B, Zhou X, Zhang X (2013) Determination of dynamic intake fraction of cookinggenerated particles in the kitchen. Build Environ 65, 146-53. [CrossRef]

8) Gao J, Cao CS, Wang L, Song TH, Zhou X, Yang J, Zhang X (2013) Determination of size-Dependent source emission rate of cooking-generated aerosol particles at the oilheating stage in an experimental kitchen. Aerosol Air Qual Res 13, 488-96.

9) Moschandreas DJ, Relwani SM, Billick IH, Macriss RA (1987) Emission rates from range-top burners - assessment of measurement methods. Atmos Environ 21, 285-9. [CrossRef]

10) Yamanaka S, Hirose H, Takada S (1979) Nitrogen oxides emissions from domestic kerosene-fired and gasfired appliances. Atmos Environ 13, 407-12. [Medline] [CrossRef]

11) Traynor GW, Anthon DW, Hollowell CD (1982) Technique for determining pollutant emissions from a gas-fired range. Atmos Environ 16, 2979-87. [CrossRef]

12) Li YG, Delsante A (1996) Derivation of capture efficiency of kitchen range hoods in a confined space. Build Environ 31, 461-8. [CrossRef]

13) Li Y, Delsante A, Symons J (1997) Residential kitchen range hoods: buoyancy-capture principle and capture efficiency revisited. Indoor Air 7, 151-7. [CrossRef]

14) Madsen U, Breum NO, Nielsen PV (1994) Local exhaust ventilation: a numerical and experimental study of capture efficiency. Build Environ 29, 319-23. [CrossRef]

15) Delp WW, Singer BC (2012) Performance assessment of U.S. residential cooking exhaust hoods. Environ Sci Technol 46, 6167-73. [Medline] [CrossRef]

16) Hunt GR, Ingham DB (1996) Long range exhaustion- a mathematical model for the axisymmetric air flow of a local exhaust ventilation hood assisted by a turbulent radial jet. Ann Occup Hyg 40, 171-96.

17) Abanto J, Marcelo R (2006) Numerical investigation of the flow in a kitchen hood system. Build Environ 41, 288-96. [CrossRef]

18) Chen JK, Huang RF, Dai GZ (2010) Flow characteristics and spillage mechanisms of wall-mounted and jet-isolated range hoods. J Occup Environ Hyg 7, 651-61. [Medline] [CrossRef]

19) Huang RF, Dai GZ, Chen JK (2010) Effects of mannequin and walk-by motion on flow and spillage characteristics of wall-mounted and jet-isolated range hoods. Ann Occup Hyg 54, 625-39. [Medline] [CrossRef]

20) Huang RF, Nian YC, Chen JK (2010) Static condition differences in conventional and inclined air-curtain range hood flow and spillage characteristics. Environ Eng Sci 27, 513-22. [CrossRef]

21) Huang RF, Nian YC, Chen JK, Peng KL (2011) Improving flow and spillage characteristics of range hoods by using an inclined air-curtain technique. Ann Occup Hyg 55, 164-79. [Medline] [CrossRef]

22) European Committee for Standardization(2003) EN: 14175-3:2003 fume cupboards - part 3: type test methods. European Committee for Standardization, Brussels.

23) Yuan SW (1967) Foundations of fluid mechanics. PrenticeHall, New York.

24) Lighthill MJ (1963) Attachment and separation in threedimensional flow. In Laminar boundary layers, Rosenhead L (Eds.), 73-82, Oxford University Press, Cambridge.

25) Perry AE, Steiner TR (1987) Large-scale vortex structures in turbulent wakes behind bluff bodies. part 1. vortex formation processes. J Fluid Mech 174, 233-70. [CrossRef]

26) Hunt CR, Abell CJ, Peterka JA, Woo H (1978) Kinematical studies of the flows around free or surface-mounted obstacles: applying topology to flow visualization. J Fluid Mech 86, 179-200. [CrossRef]

27) Newman BG (1961) The deflection of plane jets by adjacent boundaries - Coanda effect. In Boundary layer and flow control: its principles and application, Lachmann GV, (Eds.), 232-64, Pergamon Press, New York. 